\title{
Accumulation of chemical elements in tree waste of Pinus sylvestris L. growing in various ecological zones
}

\author{
Elena Kolmogorova* \\ Federal Research Center of Coal and Coal Chemistry SB RAS, 10 Leningradsky Ave, Kemerovo, \\ 650065, Russia
}

\begin{abstract}
We investigated the pattern of phosphorus, nitrogen and ashes accumulation in tree waste of Pinus sylvestris L. growing in various ecological zones. The studied areas were located in the Kemerovo Region: on flood-land of the Tom River (the Kuzbass Botanical Garden) and on the waste dump of the Kedrovsky open-cast mine. It was shown that the chemical composition of tree waste of Pinus sylvestris L. is correlated with ecological conditions of its vegetation. So, the tree waste of Pinus sylvestris L. growing on the waste dump is characterized by three-fold increased level of nitrogen compared to ones from the Kuzbass Botanical Garden. The concentration of phosphorus and ashes showed no differences between groups. We suggested that the diversity in destruction of tree waste proceeding in different conditions and microbial cenosis leads to differentiated accumulation of chemical elements in the tree waste.
\end{abstract}

\section{Introduction}

Trees can not only significantly influence on the flora of lower layers due to changing the water, thermal and light conditions of biogeocenoses, but also can form a significant amount of tree waste containing various chemical elements returning to the soil $[1,2]$. These elements are washed out from dead leaves and formed during decay of plant residues by fungi and bacteria. The chemical elements from tree waste influence to surrounding plants, change characteristics of soil and create conditions for formation of microbial cenosis [3]. On the other hand, trees themselves can grow in different environmental conditions (humidity, temperature and characteristic of soil).

Moreover, ecological conditions of vegetation determine the characteristic of microbial cenosis that can influence to flora $[1,2]$.

While the transformation of ash elements from plant residues is well described in the literature, the issue of changes in a pattern of organic elements in tree waste during plant destruction is poorly studied.

\footnotetext{
${ }^{*}$ Corresponding author: kolmogorova elena@bk.ru
} 
At the initial stage of tree waste destruction, readily soluble and mobile compounds are transformed; then biochemical processes are decelerated [4]. The intensity of destruction and mineralization of plant residues is probably associated with hydrothermal and air regimes of a particular biogeocenoses. We supposed that the quantity of free moisture and microbial activity are the important environmental factors influencing the chemical structure of tree waste during its destruction. At the same time, microbial activity is determined by relief, moisture, thermal regime and characteristic of the soil.

\section{Materials and Methods}

The samples of tree waste were selected from the underwood of Pinus sylvestris L. (II class of age) growing on the waste dump of the Kedrovsky open-cast mine and in the Kuzbass Botanical Garden.

The studied areas were located in the central part of the Kemerovo region, The Kuzbass Botanical Garden placed on flood-land of the Tom River is characterized by no moisture deficit and temperature fluctuations. The Kedrovsky open-cast mine in located $25 \mathrm{~km}$ north-east of Kemerovo and characterized by the decreased moisture and atmospheric precipitation. For these areas, the different soil characteristics are noted: technogenic soils of the Kedrovsky open-cast mine is consisted of a heterogeneous mass of sandstones, mudstones and conglomerates with a certain proportion (up to $5 \%$ ) of loams and clays; the soils of the Kuzbass Botanical Garden is made of sandstone, siltstone and mudstone; the channel facies of alluvium is represented by pebbles, gravel and sand, the floodplain facies - by sandy loam and gray loams.

The studied areas were divided according to crown density: sparse stands (open stands) with 20-30\% crown closure; medium-closed stands with 50-60\% crown closure and dense stands with $80-90 \%$ crown closure. According to this gradation, seven plots on the waste dump and seven plots in the Kuzbass Botanical Garden were selected. In the sparse stands we chose under-crown, near-crown and outer zones, in the medium-closed and dense stands - only under-crown and near-crown ones [5].

The tree waste samples were collected in May 20, July 20 and September 20 - at the beginning, the middle and the end of vegetation. The studying plots were disposed according to a phytogenous zoning; discount areas with a size of $30 \times 60 \mathrm{~cm}$ were laid with an orientation across the radial line under the model trees. Laboratory preparation of samples included its drying to an air-dry state and weighing. Analytical probes were isolated from the average-sized samples and grinded to $1 \mathrm{~mm}$ fractions.

The absolutely dry weight of the samples was determined using a drying cabinet at $+105^{\circ} \mathrm{C}$ for 4 hours and VM213M-II laboratory balance. The total amount of nitrogen and phosphorus was determined in the analyzed samples by wet ashing [6]. The ash content in tree waste was determined according to the State Standard No. 24027.2-80.

It was shown that the tree waste of Pinus sylvestris L. growing both on the waste dump of open-cast mine and in the Kuzbass Botanical Garden is characterized by decreased amount of phosphorous in July compared to May and September.

\section{Results and Discussion}

In the tree waste obtained from the waste dump of the Kedrovsky open-cast mine, a maximum concentration of phosphorus in May was discovered in the outer-crown zone of sparse stands, in July and September - in the near-crown zone of dense stands (Fig. 1). For the Kuzbass Botanical Garden, the increased accumulation of this element was detected in May in the near-crown zone of sparse stands (Fig. 2). 


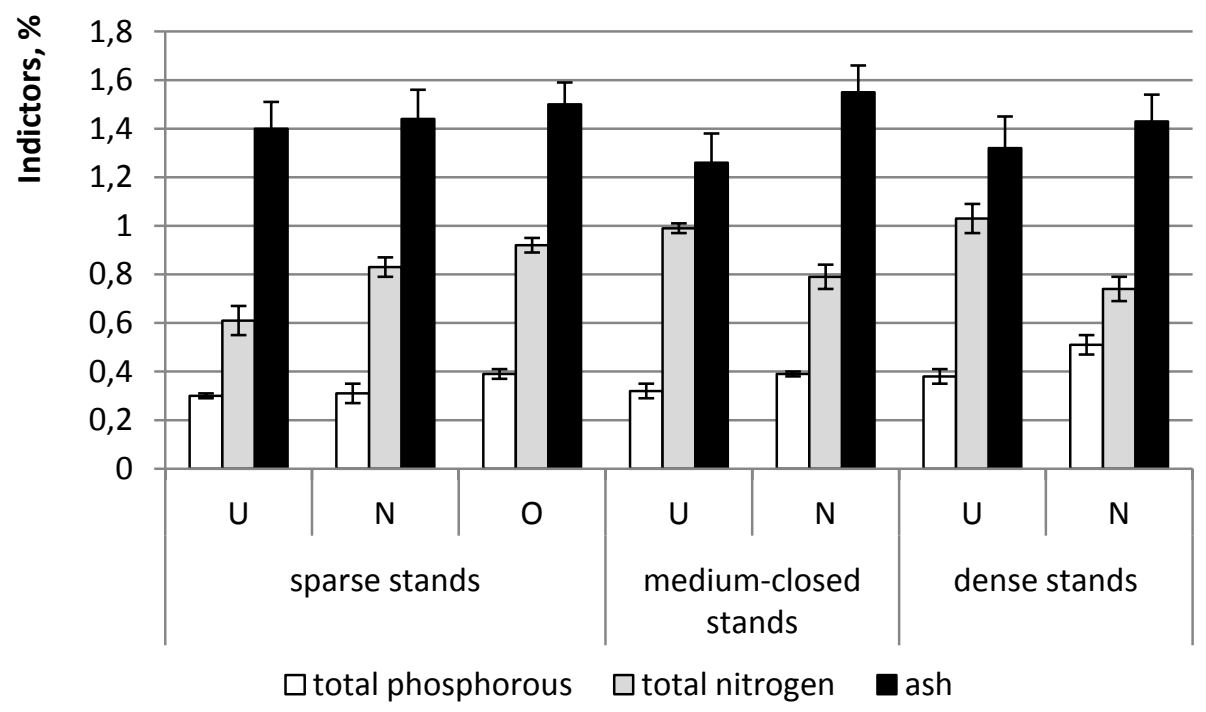

Fig. 1. Chemical composition of tree waste of Pinus sylvestris L. growing on the waste dump (average values May-September 2017 - 2020). Note: $U$ - under-crown zone; $N$ - nearcrown zone; $\mathrm{O}$ - outer zone.

According to the average values May-September 2017-2020, the maximum concentration of phosphorous in the tree waste were detected in the near-crown zone of dense stands growing on the waste dump $-0.51 \%$ (Fig. 1). Comparative analysis shown insignificant variation of the phosphorous amount in the tree waste of Pinus sylvestris L. growing on the waste dump and in the Kuzbass Botanical Garden (from $0.29 \%$ to $0.51 \%$ ) (Fig. 1, 2).

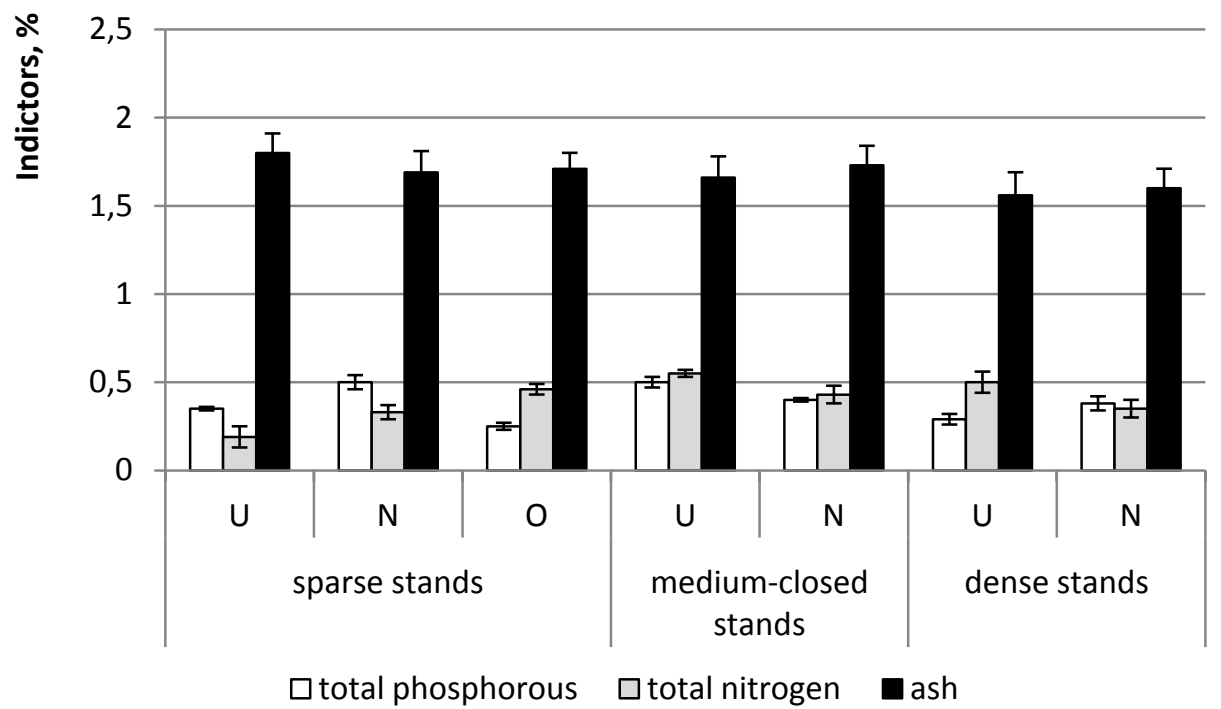


Fig. 2. Chemical composition of tree waste of Pinus sylvestris L. growing in the Kuzbass Botanical Garden (average values May-September 2017 - 2020). Note: U - under-crown zone; $N$-near-crown zone; $O$ - outer zone.

It was studied that nitrogen was accumulated equally on all studied plots from the waste dump from May to September (from $0.50 \%$ to $1.54 \%$ ) (Fig. 1). On average, the highest amount of nitrogen was registrate in the under-crown zone of medium-closed stands.

We discovered the irregular accumulation of nitrogen in the tree waste collected in the Kuzbass Botanical Garden. All studied plots with the exception of the under-crown zone of sparse stands were characterized by decreased accumulation of this element in September (Fig. 2). Comparative analysis shown 1.8 - 3.2-fold decreased nitrogen concentration in the tree waste collected in the Kuzbass Botanical Garden compared to the waste dump of the Kedrovsky open-cast mine (Fig. 1,2).

No significant changes in the accumulation of ash in tree waste during vegetation (1.18 $-2.12 \%$ ) at 14 studied plots were discovered. Moreover, we found no significant differences between plots. Ash concentration in the tree waste from the Kuzbass Botanical Garden was $0.8-1.3$-fold increased in comparison to the waste dump (Fig. 1, 2).

\section{Conclusion}

So, the differentiated accumulation of chemical elements in tree waste can be explained by variations in the destruction of plant residues due to differ of environmental conditions and participation in destruction process of differ microbial cenosis. Destruction of tree waste that are consisting a lot of essential nutrients leads to their re-assimilation and stable functioning of Pinus sylvestris L. plantations growing in the different environmental conditions.

We concluded that ecological conditions of vegetation can effect on chemical composition of tree waste of Pinus sylvestris L. Environmental conditions are the main factor of nitrogen accumulation in tree waste. We found no changes in the accumulation of phosphorous and ash. Finally, the different concentration of biologically active substances coming in the environment in the different conditions of vegetation can effect to plans and microbial cenosis, as well as determine the forest conditions.

This work was supported by the State Task No. 0286-2021-0010 "Development of scientific foundations for assessing the status and restoration of floristic diversity in situ and ex situ in regions with a high level of ecosystem degradation resulting of anthropogenic and technogenic exposure".

\section{References}

1. V.M. Lebedev, E.V. Lebedev, Agrochemistry, 4, 85-91 (2015)

2. Rice E. Allelopathy (Moscow, 1978)

3. M.M. Telitchenko, S.A. Ostroumov, Introduction to Problems of Biochemical Ecology, (Moscow, 1990)

4. S.V. Blagodatsky, Microbial biomass and modeling of the nitrogen cycle in soil (Pushchino, 2011)

5. E.Yu. Kolmogorova, V.I. Ufimtsev, Successes of modern natural science, 11 (2), $267-$ $272(2018)$

6. V.V. Kidin, Workshop on Agrochemistry (Moscow, Kolos, 2008) 